\title{
LIVRO SOBRE NADA: \\ PRETEXTO PARA INOPEROSIDADE NO TEMPO-ESPAÇO
}

\author{
Valdegilson da Silva Costa* \\ Vera Bastazin
}

RESUMO: Este artigo analisa o projeto literário de Manoel de Barros em Livro sobre nada (1996), obra cuja nota introdutória, em prosa poética, denominada Pretexto, propõe-se a atingir significações silenciadas e, simultaneamente, ampliadas, posto que, via silêncio, os significados se desalojam de convenções e adquirem sentidos em plena incompletude, por isso, adotamos como metodologia a análise da nota introdutória da obra, em que o artifício adotado pelo poeta para "atingir o nada mesmo", ampara-se no conceito de inoperosidade, proposto por AGAMBEN (2018), de acordo com o qual a potência-de-não é a amplitude contemplativa e, simultaneamente, uma reação à obrigatoriedade de dizer. Livro sobre nada coloca em suspensão a função comunicativa da linguagem verbal e edifica a crise da palavra, por isso, age de forma a transformar, substancialmente, a realidade via discurso poético, pois sua ação é a busca por aquilo que está por vir na obra, por uma matéria que se anuncia, mas não se consolida, a exemplo do que propõe BLANCHOT (2005), de que resulta um inacabamento que cala aquilo mesmo que se profere por meio de imagens que atravessam o sujeito lírico sob forma de resquícios espácio-temporais.

PALAVRAS-CHAVE: Inoperosidade; Manoel de Barros; Silêncio.

\section{Introdução}

A poesia de Manoel de Barros é, costumeiramente, abordada sob perspectivas que ora acentuam seu caráter regional, ora a situam como a escritura do minimalismo. Conquanto ambas as abordagens tenham lançado contribuições à fortuna crítica do poeta, muito daquilo que nelas se enfatiza tende à totalização, ao esgotamento de perspectivas, sem que se dê destaque aos movimentos poéticos que nascem, de fato, no vínculo do poeta com o pantanal sob um prisma minimalista, conforme se vê em Compêndio para uso dos

\footnotetext{
* Mestrando em Letras (Literatura e Crítica Literária) pela Pontifícia Universidade Católica de São Paulo (Puc-SP). Professor de Ensino Fundamental II e Médio das redes pública e privada de São Paulo.

** Doutora em Comunicação e Semiótica/Literatura, pela Pontifícia Universidade Católica de São Paulo (PucSP). Professora Associada da Puc-SP. Realizou estágio pós-doutoral, com Bolsa FAPESP, na Universidade do Minho, em Braga, sob a supervisão do Prof. Dr. Vitor Manoel de Aguiar e Silva. Suas pesquisas estão centradas no romance contemporâneo. É líder do Grupo de Pesquisa "Categorias da Narrativa", inscrito no Diretório do Grupos de Pesquisa do Brasil/ CNPq, desde 2008.
} 
pássaros (1960), obra em que as inusitadas imagens recriam o vasto mundo de longos rios que invadem mente e olhos do menino: "Escuto o meu rio:/ é uma cobra/ de água andando/ por dentro de meu olho" (Barros, 2010, p. 91). O silêncio é audível e coisificado, torna-se rio, movimenta-se tal qual serpente e, narcisicamente, reside no corpo do infante. Entrelaçam-se rio, cobra e menino graças à pausa contemplativa. A beleza dos versos é inegável, porém não se questiona, neste trabalho, a qualidade ou o efeito estético que produzem. Aquilo a que se objetiva é apontar o recrudescimento do processo de criação na trajetória do poeta, que culmina em Livro sobre nada (1996).

A análise da obra aponta certa exasperação escritural de acordo com a qual não basta construir um mundo inusitado via escritura, é preciso ultrapassar os limites da ordem linguística e perceptiva vigente para atingir o nada, matéria inapreensível, apesar de necessária para originar significações no projeto literário do escritor.

Partindo-se deste prisma, Livro sobre nada inaugura uma perspectiva na trajetória escritural de Manoel de Barros, pois as obras posteriores - Retrato do Artista quando coisa (1998) e Ensaios fotográficos (2000) - evidenciam o vínculo entre poesia e artes visuais, especificamente, a fotográfica. Apesar de pouco usual na acepção fotográfica, o termo retrato, a exemplo da expressão ensaio fotográfico, indicia a suspensão do fluxo dos acontecimentos. A fotografia é um signo que, nos dizeres de Barthes (1984 p.13), "reproduz mecanicamente o que nunca mais poderá repetir-se existencialmente". A reprodução do spectrum captura um espetáculo; fixa-o em um plano acessível ao espectador à distância. Phainómenos: do grego phainos, ou seja, fazer brilhar, dar a conhecer pela palavra. Retratar é, nessa acepção, relutar contra a mobilidade de uma ideia, de um eidós, dar-lhe feições de vídeo, isto é, tornar visível aquilo que é invisível. Não por acaso, o termo occulum (olho) possui a mesma raiz etimológica de occultus (oculto), do que é possível concluir que aquilo que nos é revelado possui uma parcela oculta, recuperável por meio da contemplação, da admiração, isto é, do mirari: espantar-se, estranhar, ver o milagre (miraculum) no templo dos tempos.

A recuperação etimológica, um tanto phantasiosa, fundamenta-se em uma premissa essencial: a imagem é um nada (esqueçamos quaisquer leituras niilistas), um retorno daquilo que não se pode reviver, apesar de afeiçoado por persistentes marcas espaço-temporais. $\mathrm{O}$ 
nada é o lugar em que tudo cabe, em que as significações estão em plena ebulição, antes mesmo de assumirem forma.

Retomemos os dois títulos. No primeiro, o retrato que nos é oferecido é do artista quando coisa. $\mathrm{O}$ artista não é flagrado no momento de sua criação, mas quando se confunde com ela, quando entre ele e a obra já não há limites. Ele é a própria "coisa” que cria. Mais que isso: existe porque é obra, é "coisa" artística. A analogia insere o poeta no tempoespaço da arte, um mundo de que é criador exclusivo, não sem deixar de ser dele o fruto. A tensão autor/obra ressurge no título Ensaios Fotográficos, pois se no primeiro caso, a tensão tende a justapor mundo criado e criação, no segundo, o termo "ensaio" adensa a crise. Apreendido como rascunho ou trabalho em processo, aquilo que antecede ao evento, o título remete ao inacabamento das significações assumidas pelas imagens poéticas. No entanto, o ensaio também é um gênero textual, marcado pela despretensão de esgotar um tema. A condição de esboço confere-lhe abertura a inúmeras conclusões, interpretações, situando-se mais como um lugar aberto a múltiplas vozes e à profunda crise criacional do que a pontos de chegada.

Diríamos que é um tipo de escritura que não pacifica perspectivas nem temáticas, pois é desfocada, posto que diz sem a obrigação de dizê-lo. Faz-se por meio da instauração de bifurcações estilísticas, de imagens que instituem o desalojamento do lugar-linguagem por meio do qual o mundo é concebido pelo sujeito lírico. A palavra "arrombada a ponto de escombro" (Barros, 1996, p. 57) é coisa prestes a desabar. Não é só palavra, é desmoronamento constante. Dela o poeta faz uso, mas dela se desfaz, porque dela se transfere e a elas retorna incessantemente. As interpenetrações, ressonâncias e invasões simbólicas advindas de um eu que não se identifica consigo mesmo, potencializam-no como poder ser permanente.

Sobre a relação imagem/ser, Octavio Paz (2015, p. 48) esclarece que a imagem poética recupera "um extremo de ser e em ser até o extremo. Extremos da palavra e palavras extremas, voltadas sobre as próprias entranhas, mostrando o reverso da fala: o silêncio e a não-significação". O poeta é aquele a quem cabe viver os extremos da linguagem para reduzir a distância entre a palavra e a coisa. 
Livro sobre nada materializa muito do que afirmamos até aqui. Sobre a relação autor /obra, esclarece Manoel de Barros:

Penso que para trouver la langue não é preciso abrir mão de temas. O tema de um poeta é ele mesmo. Até que seria bom estar no mundo só fazendo parte da paisagem, que nem uma pedra no morro. Mas a gente não é apenas aspecto. Não somos uma coisa com ninguém dentro. Nossa essência precisa de ser exercida. E a gente exerce essência quando cria solidão, como quando abre o amor. Se através da linguagem de nossa poesia a gente conseguir se expor, o mundo se refletirá em nossas palavras. (BARROS, 2010, p. 22)

A expressão francesa trouver la langue (encontrar a língua, a linguagem) demonstra a incessante busca por uma linguagem que, longe de pacificar o mundo, intenta edificar uma realidade que, via escritura, cria solidão, pois inaugura perspectivas a partir do que é essencial ao sujeito lírico e dele transborda. É na linguagem que o sujeito se constitui. Neste caso, um sujeito que emudece a linguagem para mais falar. O poeta é o visível oculto. É sujeito perceptivo que, para Collot (2013, p.20) “não está diante de um espetáculo exterior, mas imerso em um meio ambiente (...)" irredutivelmente marcado por uma percepção "um modo de pensar intuitivo, pré-reflexivo, que é a fonte do conhecimento e do pensamento reflexivo, e ao qual é vantajoso que retornem para se fortalecer e renovarem" (COLLOT, 2013, p. 18). A percepção como movimento externo e interno conduz à renovação, a pensar o mundo de outro modo. Modo esse em que o poeta é um ser de aproximações e distâncias de si e do entorno. Escrever uma obra cujo título é Livro sobre nada é no mínimo intrigante. A estranheza advém de um livro cujo título é o próprio termo livro, mas não é um livro qualquer: é sobre nada. O tema do livro nos é ofertado de antemão: o nada, de tal forma que, a negação de qualquer conteúdo, imposta na capa é, em si, matéria de poesia: não possui conteúdo, é uma desobrigação de comunicar, é a negação do dogmatismo estilístico, pois sonha com uma língua em que não haja "nem reis nem regências" (Barros, 2010, p. 36).

Em linhas gerais, a obra toma para si aquilo que Agamben define como inoperosidade ou potência-de não. Para o pensador italiano, a poesia é uma suspensão e uma exposição da 
língua, pois em seu cerne está a potência-de-não, isto é "uma resistência interna à potência, que impede que esta se esgote simplesmente no ato e a impele a voltar-se para si mesma , a fazer-se potentia potentia, a poder a própria impotência" (2018, p. 73). A ação substancial da obra estaria em não se esgotar, em não operar a linguagem com vistas à comunicação, mas a transformar substancialmente a função da linguagem por meio de uma rebeldia que se opera na linguagem/pensamento/imagem para desedificar o mundo. Afinal, arremata o teórico

O que é, de fato, poesia, se não uma operação na linguagem, que desativa e torna inoperantes funções comunicativas e informativas desta, abrindo-se para um possível novo? Ou, nos termos de Espinosa, o ponto em que a língua tendo desativado suas funções utilitárias, repousa em si mesma, contempla sua potência de dizer. (AGAMBEN, 2081, p.80)

Assim sendo, escrever sobre o nada é escrever sobre a potência de dizer e de não dizer, é alçar a língua a um arejamento, a uma contemplação de si própria pela suspensão do dizer. Não dizer é muito mais que dizer: pois é ponto em que os significados flutuam, são postos em pressão infinita para ressurgirem como nome, de acordo com aquilo que Agamben (2018, p. 88) propõe.

\section{Em busca de um Pretexto}

Dividida em quatro seções, a obra apresenta os seguintes títulos: I- Arte de infantilizar formigas, cuja temática central é a infância e a naturalidade das invencionices poéticas; IIDesejar ser, em que o eu lírico volta a olhar para "inutensílios", paro o obsoleto e arcaico, conferindo-lhes, em razão dessas características, atributos poéticos; III- O livro sobre nada, cuja aproximação com o título da obra é evidente, razão pela qual a multiplicidade temática assume a brevidade aforística, própria aos provérbios, nos quais a expressividade resulta da condensação por meio da qual se consolidam jogos sonoros e apelos imagéticos; IV- Os

Outros: o melhor de mim sou Eles, nesta seção surgem seres imaginários, tais como o lendário "Homem-do-saco", andarilhos, "homens dados a pedra" ("loucos de pedra"). 
Esquematicamente, a obra parte do universo infantil, marcado por "sandices" poéticas e a elas retorna por meio da ruptura com a ordem de funcionamento do universo, já que os poemas da última seção recriam, formal e tematicamente, a perambulação de andarilhos e insanos recobertos por trastes, restos de poeticidade. Para os fins deste trabalho, elege-se o poema Pretexto- nota introdutória de caráter poético- embrião do ciclo poético criado na estrutura de Livro sobre nada. Apontar os procedimentos poéticos por meio dos quais o poeta constrói o nada - tempo-espaço de silêncio e inoperosidade -, bem como a crise entre universo natural e artificialmente construídos.

\section{Pretexto}

O que eu gostaria de fazer é um livro sobre nada. Foi o que escreveu Flaubert a uma amiga sua em 1852. Li nas Cartas exemplares organizadas por Duda Machado. Ali se vê que o nada de Flaubert não seria o nada existencial, o nada metafísico. Ele queria o livro que não tem quase tema e se sustente só pelo estilo. Mas o nada de meu livro é nada mesmo. É coisa nenhuma por escrito: um alarme para o silêncio, um abridor de amanhecer, pessoa apropriada para pedras, o parafuso de veludo, etc, etc. O que eu queria mesmo era fazer brinquedos com as palavras. Fazer coisas desúteis. O nada mesmo. Tudo que use o abandono por dentro e por fora. (BARROS, 1995, p. 7)

A maneira despretensiosa por meio da qual a nota introdutória/poema é elaborada destaca "coisa nenhuma por escrito", alegação contraditória, posto que pertencente a uma obra literária. Escrever uma obra literária cuja matéria central é o nada e, ao mesmo tempo, afirmar que coisa alguma será escrita é pôr em xeque a relação entre obra dada como matéria palpável e obra por fazer-se ou, até mesmo, por fazer-se em plena negação. Em outras palavras, é evidenciar o diálogo entre potência, impotência e potência-de-não. O problema instituído por Barros evidencia aquilo que seria a condição mesma da poesia moderna. Envolta em um mal-estar decorrente da "falta de poesia ou da poesia que falta" (Siscar, 2007, p.177), a poesia tomou para si o direito social de não falar, de manter-se plena, de forma que, manter-se em suspensão é ampliar as possibilidades do ato de criação poética, mas é também realçar a poesia como lugar da própria crise poética. $\mathrm{O}$ nada converte-se em obra literária, matéria de poesia pode ser "poesia que falta", repleta de inerências, afinal a 
concretude, a materialização é um ato que indicia a perda de inúmeros outros, razão pela qual "Tem mais presença em mim o que me falta” (Barros, 1996, p. 67).

Ao início da nota introdutória, Manoel de Barros menciona Flaubert. O escritor francês almejava o nada: esvaziamento temático alinhado à substancialidade de determinado estilo:

O que me parece mais bonito, aquilo que queria fazer, é um livro sobre nada [...] que se realizaria pela força interna do seu estilo, como a terra sem sustentação se realiza no ar, um livro que não teria quase assunto, ou pelo menos em que o assunto seria quase invisível se isso for possível. As obras mais bonitas são aquelas onde há menos de matéria; quanto mais a expressão se aproxima do pensamento, mais a palavra cola acima e desaparece [...] Creio que o futuro da arte está nestas vias [...] Precisaria de todo um livro para desenvolver tudo o que quero dizer. Escreverei sobre isso na minha velhice, quando não tiver mais nada para rabiscar [...] (FLAUBERT, 1993, p.20)

As palavras de Flaubert sobrepõem o estilo à matéria narrada, ao enredo, ao conteúdo, se assim pudermos falar. Aquilo que é a matéria da escritura literária - a narrativa- é o próprio "acontecimento ainda por vir" (Blanchot, 2005, p.08). Ao evidenciar o desejo de construir uma obra em que se esvazia a escritura, o autor rompe com um código historicamente sistematizado: a obrigatoriedade de encaminhar um enredo, apoiando-se, segundo suas próprias palavras, no "estilo", o que leva o leitor, em razão da ausência de fio condutor da narrativa, a preencher espaços vazios, a conviver com a irregularidade, a preencher lacunas de modo nada impassível ou pacífico. Apoiando-nos nas palavras de Umberto Eco (2008, p.25), poderíamos dizer que, na proposta de Flaubert, “obra é, de certa forma um esboço do que pretendia ser e do que é de fato, ainda que os dois valores não coincidam".

Se toda produção é resposta a uma recepção, e "nenhum poeta ou artista tem sua significação sozinho” (Eliot, 1939, p. 39), resta-nos examinar a apropriação de Manoel de Barros acerca da declaração do escritor francês.

Há certa animosidade no pensamento de Barros. A pretensão do poeta é apropriarse e, ao mesmo tempo, desviar-se do pensamento de Flaubert, pois propõe o "nada mesmo". Um nada extremo, o qual assume a forma de livro. O livro, nesse sentido, tal 
qual Blanchot, seria um "livro por vir", que não está escrito, ou melhor, que se coloca num espaço limiar entre o que se escreveu e o que não pode ser escrito, instaurando a potênciade-não passar a ato, como afirma Agamben (2018, p.79) É pretexto- termo intrigante. Tomado como aquilo que encobre a real intenção pela qual se realiza algo, é recusa à clarividência, é ruptura e resistência ao fluxo de acontecimentos próprios do discurso informativo; é desvio das próprias funções da linguagem corrente. Mais que isso: é estado de mobilidade contemplativa. A atitude agudamente contemplativa, proximidade íntima com aquilo que não existe substancialmente, é digna de ser mencionada, já que o próprio poeta pantaneiro a enuncia:

Nos poetas há uma fonte que se alimenta de escuros. Coisas se movendo ainda em larvas, antes de ser ideal ou pensamento. É nessa área do instinto que o poeta está. A coisa ainda particular, corporal, ainda não generalizada e nem mentada. Aquilo que mestre Aristóteles falou: 'Todo conhecimento passa antes pelos sentidos'. O poeta é o primeiro a tocar nos íntimos. Nas pré-coisas. (BARROS, 2010, p. 58)

Assumir a ausência de forma ou o momento de indiscernibilidade (o escuro) em contraste com a claridade, com a nitidez das imagens existentes, como aspecto visceral do ato de criação poética associado ao estágio em que as coisas são larva, termo proveniente do latim larva/larvae utilizado, originalmente para designar espírito, máscara, fantasma e brinquedo. As três designações remetem à imaterialidade, àquilo que não é a coisa em si, mas que se põe em lugar dela ou que transcende. Espírito é imaterialidade, alma humana que se manifesta no corpo vivo. Máscara é vivacidade resguardada e ativada quando posta na face. Fantasmas são espectros, visões quiméricas. Tomadas em conjunto, as três definições orientam-nos a perceber a força do impalpável, do sensível, pois não são atos; são potências de privação do ato. Mas e brinquedos? Como envolvê-los nessa celeuma advinda do termo larva/ larvae? Compreendemos que brincar equivale a mudar o sentido ordinário das coisas do mundo, é jogar com os signos da realidade por meio de apreensões irreais. Ao brincar, anseios e sentimentos constituem linguagem própria. Fazer de conta é abolir o fluxo da realidade para nela inserir outra ordem: a do sonhar de olhos abertos. 
Quando associado à acepção biológica, mais comumente utilizada, o termo larva/ larvae caracteriza certos tipos de animal que ainda não desenvolveram plenamente forma e estrutura, já que em contínua metamorfose. Estamos, portanto, diante da discussão sobre estrutura e forma no universo escritural. Note-se que a forma do próprio texto em questão abole a estrutura versificada. Apresenta-se como nota de caráter metalinguístico sem, entretanto, deixar de lançar mão de procedimentos estéticos.

\section{Imagens em silêncio}

A esta altura, é válido retomar algumas imagens do Pretexto: "O que eu queria mesmo era fazer brinquedos com as palavras. Fazer coisas desúteis." Palavras em condição de brinquedo estão intimamente associadas ao lúdico. Brincar é encenar, é fazer do pedaço de madeira um cavalo, é fazer da folha de papel as asas de um pássaro. É metamorfosear, ou em termos literários, metaforizar, possibilitar à palavra e às coisas outra possibilidade de uso. O excerto antecipa aquilo que será o programa da obra: uma série de descontinuidades e instabilidades sintáticas, lexicais e semânticas, a exemplo do poema 2.3: Eu queria crescer pra passarinho (BARROS, 1995, p.30). O verbo crescer, intransitivo, é complementado pelo objeto indireto "pra passarinho", assomada a uma ampliação que, ao fundo, evidencia o desejo de transmutação ao reino das aves (passarinho), cujos seres são, proporcionalmente, menores que os humanos. A operação nos planos sintático e semântico desapropria os seres, objetos e linguagem de suas funções primeiras, utilitárias e os arrebata a uma dimensão desútil, o que não é o mesmo que inútil, mas avesso ao utilitarismo. A poesia não seria isso?

O que é, de fato poesia, se não uma operação na linguagem, que desativa e torna inoperantes funções comunicativas e informativas desta, abrindo-se para um possível novo uso? Ou, nos termos de Espinosa, o ponto em que a língua, tendo desativado suas funções utilitárias, repousa em si mesma, contempla sua potência de dizer. (AGAMBEN, 2018, p. 80)

Se anteriormente associamos pretexto a escusa, desta feita, o apontaremos como aquilo que antecede o texto, aquilo que, neste caso, antecede as seções da obra - o 
pré-texto. Trata-se de uma prefiguração que transpõe as entranhas do sujeito lírico, lançandoo à "experiência de seu pertencimento ao outro, ao tempo, ou à linguagem - o sujeito lírico deixa de pertencer a si” (COLLOT, 2004, p. 166). Vivencia a contemplação, paradoxalmente, pausa e movimento. Um sopro que furta exatamente aquilo que expõe. Graças a isso, desfazem-se as dicotomias visivel vs invisivel; obra concreta vs obra por vir; passado vs presente. A obra, de acordo com essa acepção, é sempre promessa de obra e o presente é esvaziado das próprias ocorrências, invocando potenciais encontros de diversos tempos e espaços, presentificados por meio de lapsos de devir

Viver a abolição do tempo, viver esse movimento, rápido como o 'raio', pelo qual dois instantes, infinitamente separados, vêm (pouco a pouco, embora imediatamente) ao encontro um do outro, unindose como duas presenças que, pela metamorfose do desejo, se identificassem, é percorrer toda a realidade do tempo e, percorrendo-a, experimentar o tempo como espaço e lugar vazio, isto é, livre dos acontecimentos que geralmente o preenchem. (BLANCHOT, 2005, p.17)

O encontro assinalado por Blanchot põe às claras o esvaziamento espaço-temporal, ou seja, enfatiza-o com base em uma premissa- "livre dos acontecimentos"- proposta pelo pensador como "vacância móvel, distância agitada, espaço interior em devir onde as estases do tempo se dispõem numa simultaneidade fascinante" (2005, p.17).

Após afirmar, por meio de períodos simples, contumazes, carentes de reificações, que seu livro é "nada mesmo", o sujeito lírico do poema em prosa de Manoel de Barros (2005, p.17) propõe, as seguintes (in) definições: "É coisa nenhuma por escrito: um alarme para o silêncio, um abridor de amanhecer, pessoa apropriada para pedra, o parafuso de veludo, etc etc."

O vigor poético do período/verso é digno de esforços para esboçar uma leitura daquilo que edifica o nada, materializado em livro. Chama-nos à atenção a oração que desencadeia a sequência de frases nominais: "É coisa nenhuma por escrito:" O livro existe, mas na condição de "coisa nenhuma por escrito", do que se pressupõe que a matéria da obra tensiona aquilo que está nela grafada. Noutras palavras, a escrita do livro o desfaz, desconfigura-o, ao passo que, aquilo que nele não se escreve, configura-o. Eis uma das 
aparições do nada: uma cadeia de significações instauradas entre a experiência que acompanha, antecede e sucede, a um só tempo, aquilo que fora escrito - o Livro sobre nada, aquela vacância móvel por meio da qual o que não é escrito destitui as camadas do tempo.

Não sem razão retomamos Heidegger, para quem a temporalidade, na condição de internalização originária ao ser, é "o fora de si em si e para si mesmo originário" (HEIDEGGER, 2015, p.116). O porvir, o vigor de ter sido e a atualidade intrincadas constituem aquilo que o filósofo denomina ekstases, instâncias cuja unidade não se assevera externamente ao ser, como resquícios isolados da temporalidade, mas dele advêm graças a uma unidade que amplia a projeção, de vir a ser ou até de vir a não-ser. É no porvir que as elkstases se coadunam, ampliam a projeção do para si. Trata-se de um continuum.

A indissociabilidade inerente à temporalidade confere-lhe um teor de simultaneidade: não recorta o mundo, não isola episódios, não predetermina a função nem a funcionalidade dos seres, pelo contrário, transfigura-os, desmecaniza-os continuamente, assim, opera epistemologicamente no cerne da sociedade do capital: a divisão do tempo, evidência de uma sociedade que consome segundo após segundo uma nova ordem de atribuições e de funções como sinônimo de prosperidade a que o Pretexto reage via inoperosidade.

Observemos, ainda, mais detidamente a passagem do Pretexto: “[...] um alarme para o silêncio, um abridor de amanhecer, pessoa apropriada para pedra, o parafuso de veludo, etc etc.”. A ausência de verbos de ação cria uma sequência de frases nominais, em que os acontecimentos são contidos por imagens amplamente edificadas no estranhamento, dentre as quais destacamos "[...] um alarme para o silêncio [...]". O paradoxo é a chave de entrada à leitura da imagem, já que alarme e silêncio não se conjuminam, porém o adensamento do excerto, cuja finalidade é descrever o "nada mesmo" (projeto do livro), requer maior atenção. Observe-se que o alarme, sinal mecânico que adverte sobre a ameaça de algum perigo, possui como alvo o silêncio. A atitude silente é, então, ameaçadora.

O silêncio passa a ser o iminente perigo. Pensemos o silêncio, ou melhor, as formas do silêncio. "Todo dizer é uma relação fundamental com o não-dizer" (ORLANDI, 2007, p.12). Ainda segundo a autora, isso significa que sendo ele, a incompletude, possui uma 
marca inequívoca: "é o lugar dos muitos sentidos, do fugaz, do não apreensível” (p.12). O inapreensível contido no silêncio é perigoso, ameaçador porque a atitude silente é fundante de significações. É ponto de origem. É ampliação no horizonte das significações, fundantes, razão pela qual as palavras, na acepção da pesquisadora, são permeadas por silêncio: “Assim, quando dizemos que há silêncio nas palavras, estamos dizendo que elas são atravessadas de silêncio; elas produzem silêncio. O silêncio fala por elas; elas se calam" (ORLANDI, 2007, p.15).

O silêncio, "palavra nenhuma por escrito", escorre pelas tramas das palavras e desobriga a dizer, pois significa de maneiras outras. Ao conclamá-lo, a poesia de Barros opõese ao controle, à disciplina que obriga a dizer, desagrega a ideologia da comunicação e posiciona-se em um tempo de silens, à sombra, em repouso, em contemplação, tal qual o mito, cuja atualização temporal prescinde de explanações sobre seu modo de construir significação.

\section{Considerações finais}

Conquanto validemos todas as considerações anteriores, entendemos que a riqueza das imagens da poesia barriana não pode ignorar a proximidade que com ela tem o espaço. Não se pretende, com isso, reacender leituras deterministas nem mesmo restringir a obra às condições da região por ela retratada. Nossa intenção é, antes, reconhecer a terra, o lugar da obra como conjunto simbólico, indiciado por apreensões que evidenciam uma cumplicidade entre sujeito e lugar, conforme Eric Dardel (2005, p.06) propõe: “a experiência geográfica, tão profunda e tão simples, convida o homem a dar à realidade geográfica um tipo de animação e de fisionomia em que ele revê sua experiência humana, interior e social. Os amplos e silenciosos rios, a vastidão das planícies, o inesperado canto do pássaro em meio à diversidade da vegetação, certamente, são elementos que contribuem para o ato criador do sujeito-lírico. Poderíamos adicionar à imagem "abridor de silêncio", a partir da perspectiva de Dardel, como fisionomia alusiva à noite, anunciada pelos pássaros que rasgam, abrem o céu pantaneiro, numa perspectiva, até certo ponto, primitiva, animada pela feição local, em que anoitecer é tempo de pausa, disso bem sabem os pássaros! A imagem 
não é pacificadora. Noite é, a exemplo do que afirmamos no parágrafo anterior, um tempo de vastidão, de silêncio, de perda de nitidez de formas, sobretudo, em se tratando do extenso bioma pantaneiro, interiorizado pelo poeta como linguagem escritural. O próprio Manoel de Barros, ao se referir à questão esclarece:

Gosto tanto do Pantanal ao ponto de eu precisar inventar uma tarde a partir de um tordo. Gosto do Pantanal ao ponto que eu possa ficar livre para o silêncio das árvores. Gosto tanto Pantanal ao ponto que meu idioma não sirva mais para comunicar, senão que apenas para comungar. [...] Tenho dentro de mim um lastro de brejos e de pássaros que inevitavelmente aparecem na minha poesia. (BARROS, 2010, p. 21-22)

Cabe aqui um dado biográfico: o poeta viveu maior parte no Rio de Janeiro, local, sabidamente, urbanizado. Tordo (espécie de ave), árvore, brejo e pássaro não meras lembranças na poética barriana. São lastros, alicerces da própria escritura barriana, a qual não comunica, comunga, isto é, mistura, imita, busca equivalência entre os seres/linguagem do universo pantaneiro e os do universo urbano, de que ressoa o ponto de tensão a que nos referimos anteriormente.

Podemos examinar, então, mais uma das imagens do Pretexto: “[...] um abridor de amanhecer [...]”. Abridores são instrumentos que destravam, promovem sulcos, aberturas em objetos, propiciando visões de seres ou objetos com os quais não se tem contato anteriormente à abertura. A luz da manhã, nunca idêntica a si própria, opera sob o signo da mesmidade temporal (reitera-se todos os dias) e da outridade (nunca se reitera da mesma forma, o que confere um caráter inesperado no esperado, daí sua complexidade) confere um caráter inesperado no esperado, daí sua complexidade).que confere um caráter inesperado no esperado, daí sua complexidade). Associada ao abridor, adquire, pois a aurora é da ordem do natural, complexa porque o nome que a designa não acolhe sua feição, reiteradamente inaugural, ao passo que o abridor, em sentido literal, é utensílio dotado de função específica, única. 
Há no procedimento de transmutação e recriação artística (a tekne, artifício) do espaço-tempo natural, do qual "alarme para o silêncio" e "abridor de amanhecer" são índices, algo de que Milton Santos nos adverte:

A história do homem sobre a Terra é a história de uma ruptura progressiva entre o homem e o entorno. Esse processo se acelera quando, praticamente ao mesmo tempo, o homem se descobre como indivíduo e inicia a mecanização do Planeta, armando-se de novos instrumentos para tentar dominá-lo. A natureza artificializada marca uma grande mudança na história humana da natureza. (SANTOS, 2013, p. 17)

A voz que ressoa no poema é um alarde. Convulsiona a realidade artificializada, recriando-a poeticamente por meio da inserção de vestígios de elementos naturais, persistentes "por dentro e por fora" do sujeito lírico que, por sinal, abandona aquilo mesmo que tende a dizer enquanto o diz em silêncio. A incompletude, traço marcante de Livro sobre nada, é uma grande abertura à ampliação de significações, pois as sendas do Pretexto são coisas a dizer e a ler "etc, etc".

Dessa forma, a obra não propõe o minimalismo pelo minimalismo, conforme boa parte da fortuna crítica do autor aponta, nem evoca as imagens pantaneiras como transparente saudosismo. O minimalismo é colheita de resquícios naturais, justapostos a elementos artificiais. A transposição de elementos de um universo a outro escancara uma espécie de crise e resistência à natureza artificializada, exposta sob forma de imagens cunhadas no ilogismo, como é o caso de "parafuso de veludo" - um nada inquietante. A exasperação, em tom metalinguístico, fala pouco de si. Os encontros com ares bem condicionados, recondicionam a linguagem, o tempo, o mundo, a ponto de tudo silenciar graças ao alcance do nada, de onde brota o indizível, plenamente alardeado pelo silêncio.

\section{LIVRO SOBRE NADA PRETEXT FOR INOPERABILITY IN TIME-SPACE}

ABSTRACT: This article analyzes Manoel de Barros's literary project in Livro sobre nada (1996), a work whose introductory note, in poetic prose, called, Pretexto proposes to achieve silenced and, simultaneously, amplified meanings , since, through silence, they are dislodged from conventions and acquire incompleteness, that is why we adopted as methodology the analysis of the introductory note of the work, in which, the artifice adopted by the poet to "achieve nothingness" is supported by concept of inoperability, proposed by AGAMBEM (2018), according to which the contemplative 
amplitude is a reaction to the obligation to say. Livro sobre nada puts the communicative function of verbal language in suspension and builds the crisis of the word, therefore, it acts in a way to substantially transform reality via poetic discourse, as its action is the search for what is to come in the work, for a matter that is announced, but not consolidated, like proposed by BLANCHOT (2005), which results in an unfinishing that silence what is uttered through images that cross lyrical subject in the form of spatial and temporal remains.

KEYWORDS: Manoel de Barros; Inoperability; Silence.

\section{REFERÊNCIAS}

AGAMBEN, Giorgio. O Fogo e o relato- ensaios sobre criação, escrita, arte e livros. Tradução de Andrea Santurbano e Patricia Peterle. 1.ed. São Paulo: Boitempo, 2018.

BARROS, Manoel de. Poesia completa. 1.ed. São Paulo: Leya, 2010.

. Encontros. Org. Adalberto Müller. 1.ed. Rio de Janeiro: Beco do Azougue, 2010.

BARTHES, Roland. A Câmara clara. Tradução de Júlio Castañon. 1.ed. Rio de Janeiro: 1984.

BLANCHOT, Maurice. O Livro por vir. Tradução de Leyla Perrone-Moisés. 1.ed. São Paulo: Martins Fontes, 2005.

COLLOT, Michel. Poética e filosofia da paisagem. Tradução de Ida Alves. 1.ed. Rio de Janeiro: Editora Oficina Raquel, 2013.

. O Sujeito lírico fora de si. Tradução de Michel Pucheu. 11.ed. Rio de Janeiro: Terceira margem, 2004.

DARDEL. Eric. O Homem e a terra- natureza da realidade geográfica. Tradução de Werther Holzer. 1.ed. São Paulo: Perspectiva, 2015.

ELIOT, T.S. Ensaios. Tradução de Ivan Junqueira. 1.ed. São Paulo: Art Editora, 1989.

FLAUBERT, Gustave. Correspondance. Disponível em http://flaubert.univ-rouen.fr/correspondance/conard/lettres/lettres1.html. Acesso em 09 de jun. 2020.

HEIDEGGER, Martin. Ser e tempo. Tradução de Márcia Sá Cavalcante. 10.ed. Rio de Janeiro: Vozes, 2015.

ORLANDI, Eni. Puccinelli. Formas do silêncio: no movimento do sentido. 6.ed. Campinas, SP: Editora da Unicamp, 2007.

PAZ, Octavio. Signos em rotação. Tradução de Sebastião Uchoa Leite. 4.ed. São Paulo: Perspectiva, 2015.

SANTOS, Milton. Técnica, espaço, tempo: globalização e meio técnico científico-informacional. São Paulo: Edusp, 2013. 
SISCAR, Marcos. Responda cadáver: o discurso da crise na modernidade. In: Alea, São Paulo, v. 2, p.176-189, jul-dez, 2007.

Recebido em: 27/09/2020.

Aprovado em: 22/10/2020. 